\title{
Multiseptate Gallbladder with Cholelithiasis Diagnosed Incidentally in an Elderly Patient
}

\author{
Wataru Miwa, Kyutaro Toyama, Yoko Kitamura, Kazuko Murakami, Kazuhisa Kamata, \\ Tessyu TAKada, Hiroaki Tanabe and Masaaki KanAYama
}

\begin{abstract}
A 70-year-old woman with rheumatoid arthritis was admitted to our hospital because of gastric ulcers. Abdominal echography incidentally revealed that the patient's gallbladder was multiseptate, an extremely rare anomaly. The diagnosis was confirmed by endoscopic retrograde cholangiography. This is the 26th case of multiseptate gallbladder in the world literature, but the patient is the oldest yet recorded with this condition. Furthermore, unlike most patients with multiseptate gallbladder, she had no biliary symptoms with concomitant cholelithiasis. (Internal Medicine 39: 1054-1059, 2000)
\end{abstract}

Key words: primary biliary cirrhosis, chronic hepatitis C

\section{Introduction}

Multiseptate gallbladder is an extremely rare anomaly characterized by the presence of multiple thin septa dividing the gall bladder lumen into several chambers. Right upper quadrant pain suggestive of cholecystitis is frequently associated with this anomaly, although coexistence of cholelithiasis has seldom been reported (1-3). The mean age at diagnosis is less than 40 years and in fact children are sometimes affected (4, 5 ). Here we describe a 70-year-old woman who was found incidentally to have a multiseptate gallbladder. She had been totally asymptomatic in spite of concomitant cholelithiasis, primary biliary cirrhosis and chronic hepatitis $\mathrm{C}$.

\section{Case Report}

A 70-year-old woman was referred to our division on April 22,1997 , because of black stools that had continued for several days. She had undergone blood transfusion 40 years previously following a traffic accident. About 15 years later, cholelithiasis had been discovered on an abdominal X-ray film, but there were no biliary symptoms and therefore no further investigation was performed. She had been suffering from rheumatoid arthritis for more than 20 years, and receiving several forms of medication including non-steroidal anti-inflammatory drugs (NSAIDs). She had never drunk alcohol.

At presentation she appeared well and had no abdominal symptoms. Her height was $143 \mathrm{~cm}$ and weight $38 \mathrm{~kg}$. Physical examination revealed deformities of the bilateral proximal finger joints, but no abnormal findings in the abdomen. Laboratory data disclosed hypochromic microcytic anemia and mild hepatic abnormality, especially elevation of serum alkaline phosphatase (Table 1). HCV antibody and HCV-RNA were positive. Anti-mitochondrial antibody and anti-M2 antibody were present, but the patient had no history of pruritus or jaundice.

Gastrointestinal fiberscopy demonstrated multiple deep gastric ulcers but no esophageal varices. After the patient had been hospitalized, NSAIDs were discontinued and administration of an $\mathrm{H}_{2}$ receptor antagonist was started, resulting in amelioration of the gastric ulcers. Ultrasonographic examination of the abdomen incidentally revealed multiple fine septations in the gallbladder with a honeycomb appearance, together with a gallstone (Fig. 1). The gallbladder was normal in size without wall thickening. Computed tomographic scan confirmed the multicystic appearance of the gallbladder with a calculus, as well as mild hepatosplenomegaly (Fig. 2). An oral cholecystocholangiogram demonstrated radiolucent multiple thin septa within a well opacified gallbladder (Fig. 3). There was good gallbladder contraction after ingestion of egg yolk. Endoscopic retrograde cholangiography (ERC) clearly showed at least six septations subdividing the gallbladder, especially in the body and fundus (Fig. 4). One round filling defect representing a stone was also detected in one of the chambers. A smooth indentation observed on the extrahepatic bile duct at the porta hepatis and minor irregularities in the peripheral intrahepatic bile ducts suggested a cholangiographic feature of primary biliary cirrhosis $(6,7)$. In the process of gallbladder filling during ERC, the separate chambers were visualized not simultaneously but in order, one after the other. Based on these

From the Division of Gastroenterology, Hiratsuka Kyosai Hospital, Hiratsuka

Received for publication December 13, 1999; Accepted for publication June 21, 2000

Reprint requests should be addressed to Dr. Wataru Miwa, the Division of Gastroenterology, Hiratsuka Kyosai Hospital, 9-11, Oiwake, Hiratsuka, Kanagawa 254-0047 
Table 1. Laboratory Data on Admission

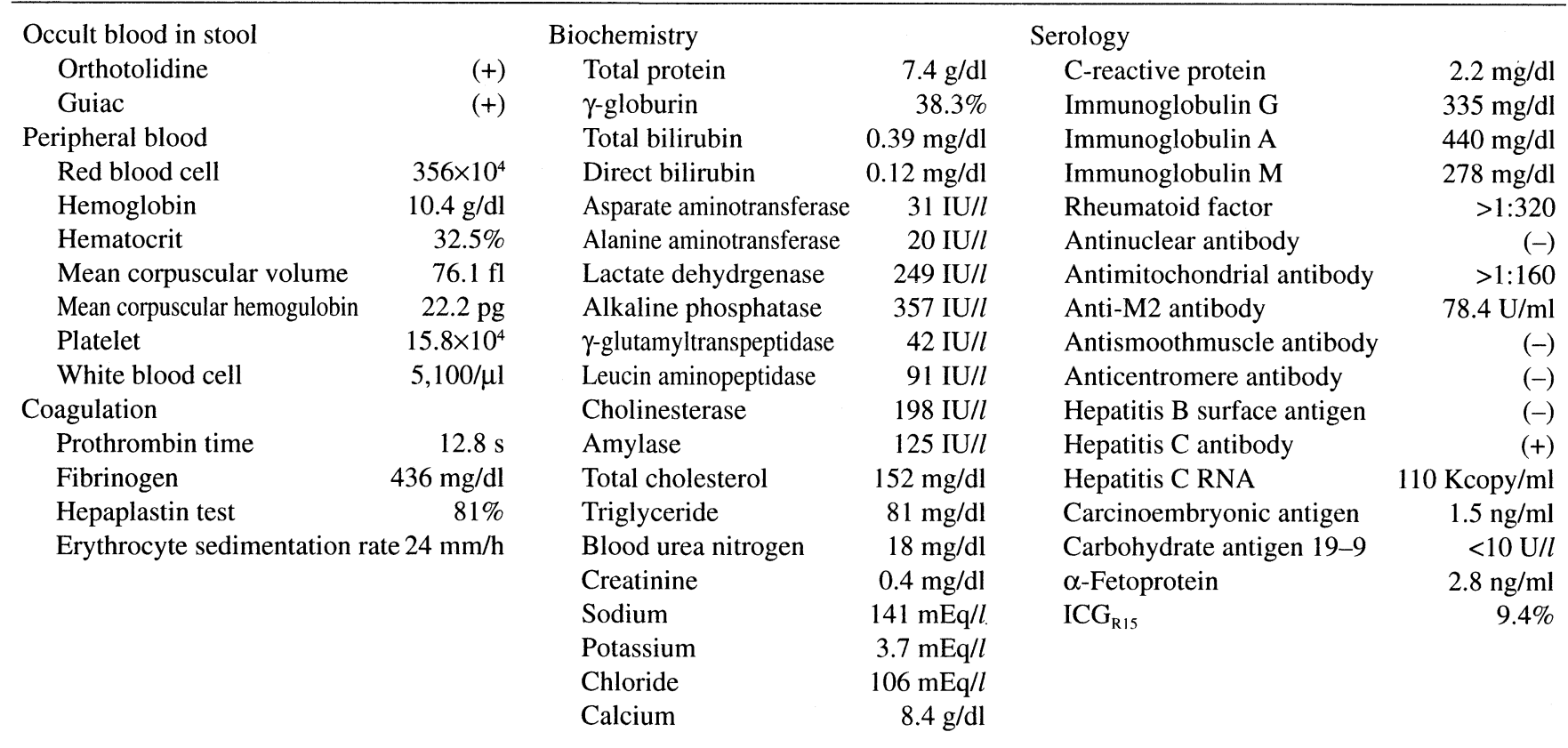

$\mathrm{ICG}_{\mathrm{R} 15}$ : indocyanine green retention rate at 15 minutes.

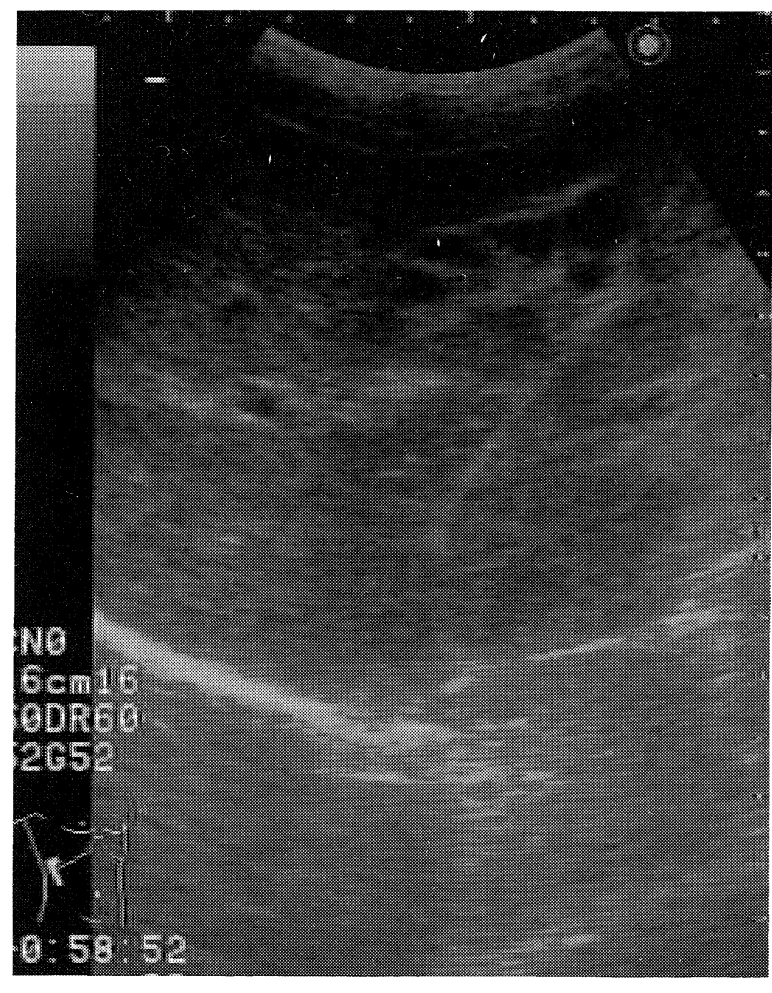

A

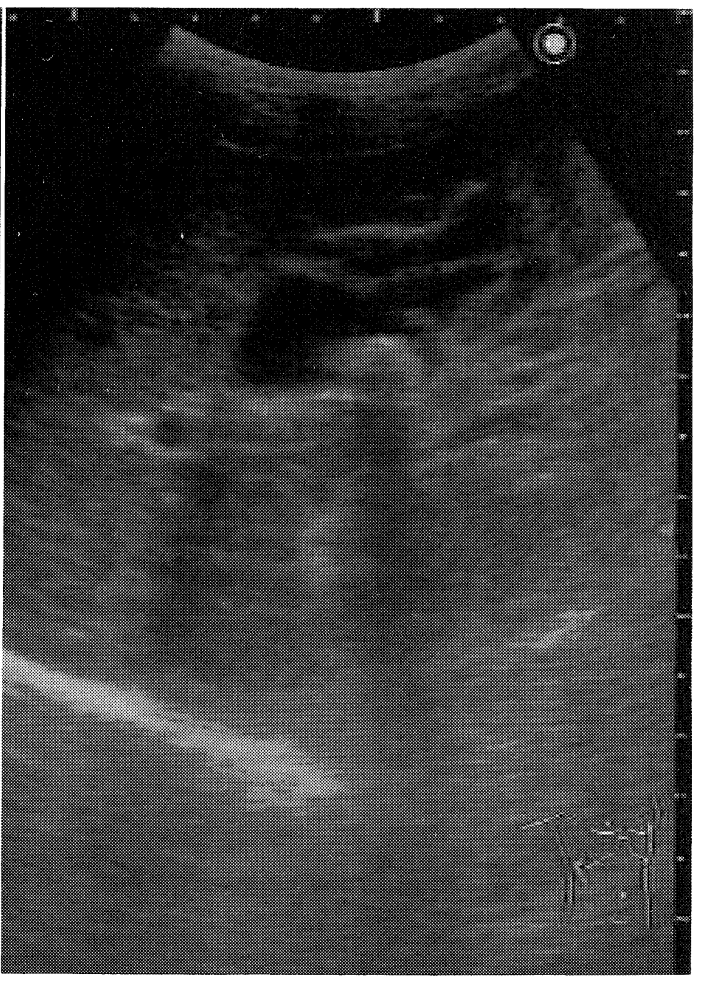

B

Figure 1. Ultrasonographic appearance of the gallbladder. Multiple thin septations are demonstrated in the gallbladder with a honeycomb appearance (A). Solitary gallstone casting a discrete acoustic shadow is also evident (B). 

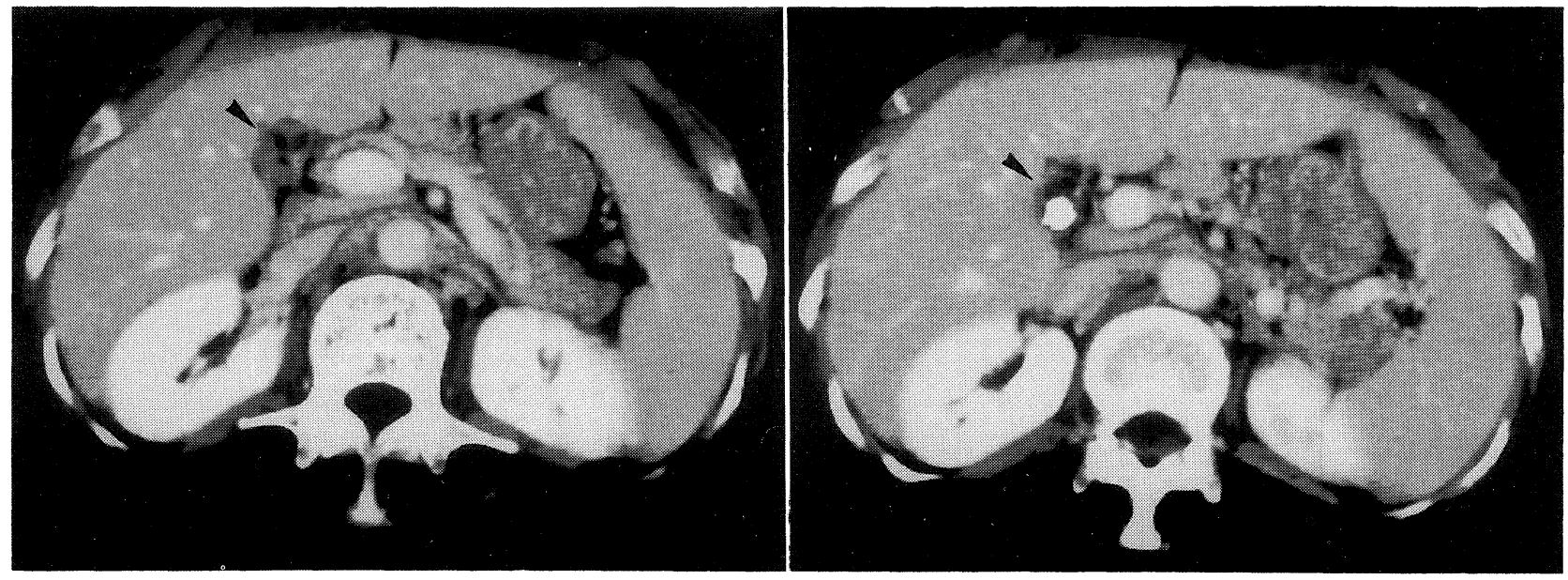

Figure 2. CT scan of the abdomen shows a multicystic appearance of the gallbladder with a calculus (arrowhead). Hepatosplenomegaly is also observed.

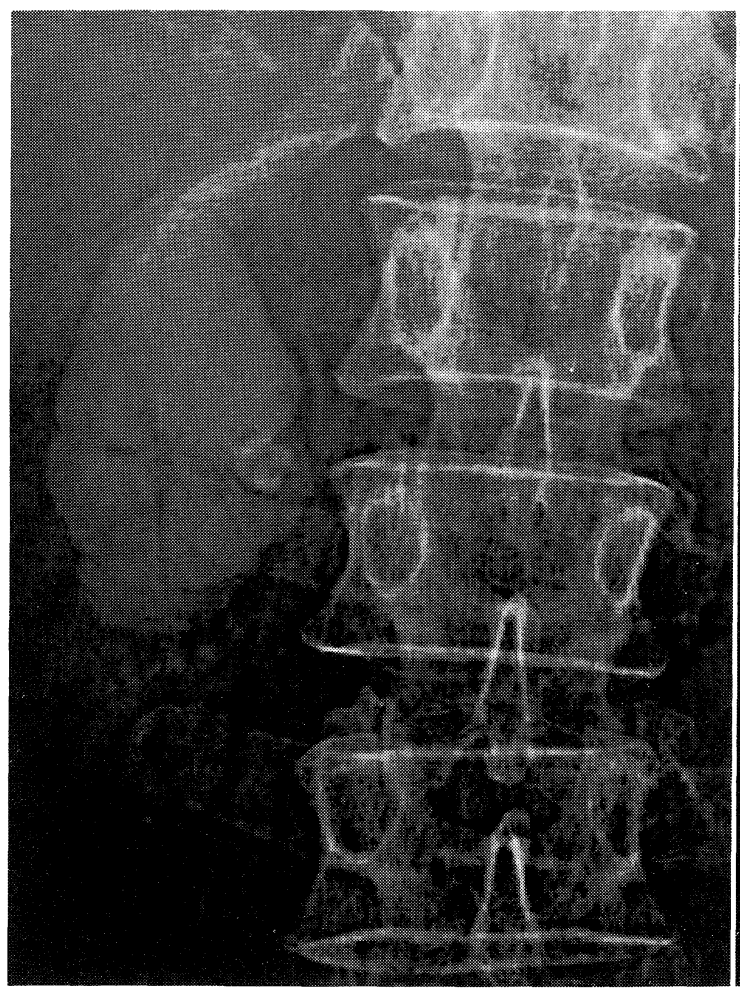

A

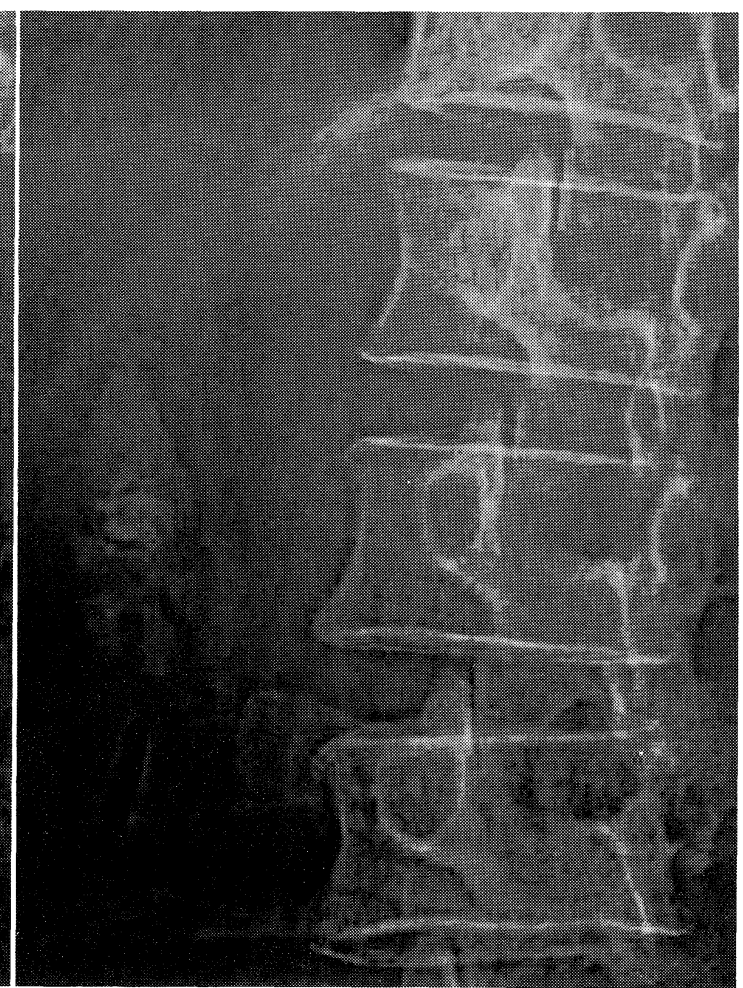

$\mathrm{B}$

Figure 3. Oral cholecystogram. Multiple radiolucent septations and a radioopacified stone are detectable within the gallbladder (A). Good contraction occurs after ingestion of egg yolk (B).

findings, a diagnosis of multiseptate gallbladder was made. Since the patient had been totally asymptomatic, we did not recommend cholecystectomy.

During the period of hospitalization, liver biopsy was per- formed to investigate the patient's hepatic abnormality. The portal tract was enlarged by a lymphoid aggregate with occasional disruption of the limiting plate of hepatocytes. Interlobular bile duct damage was prominent, with surrounding lym- 

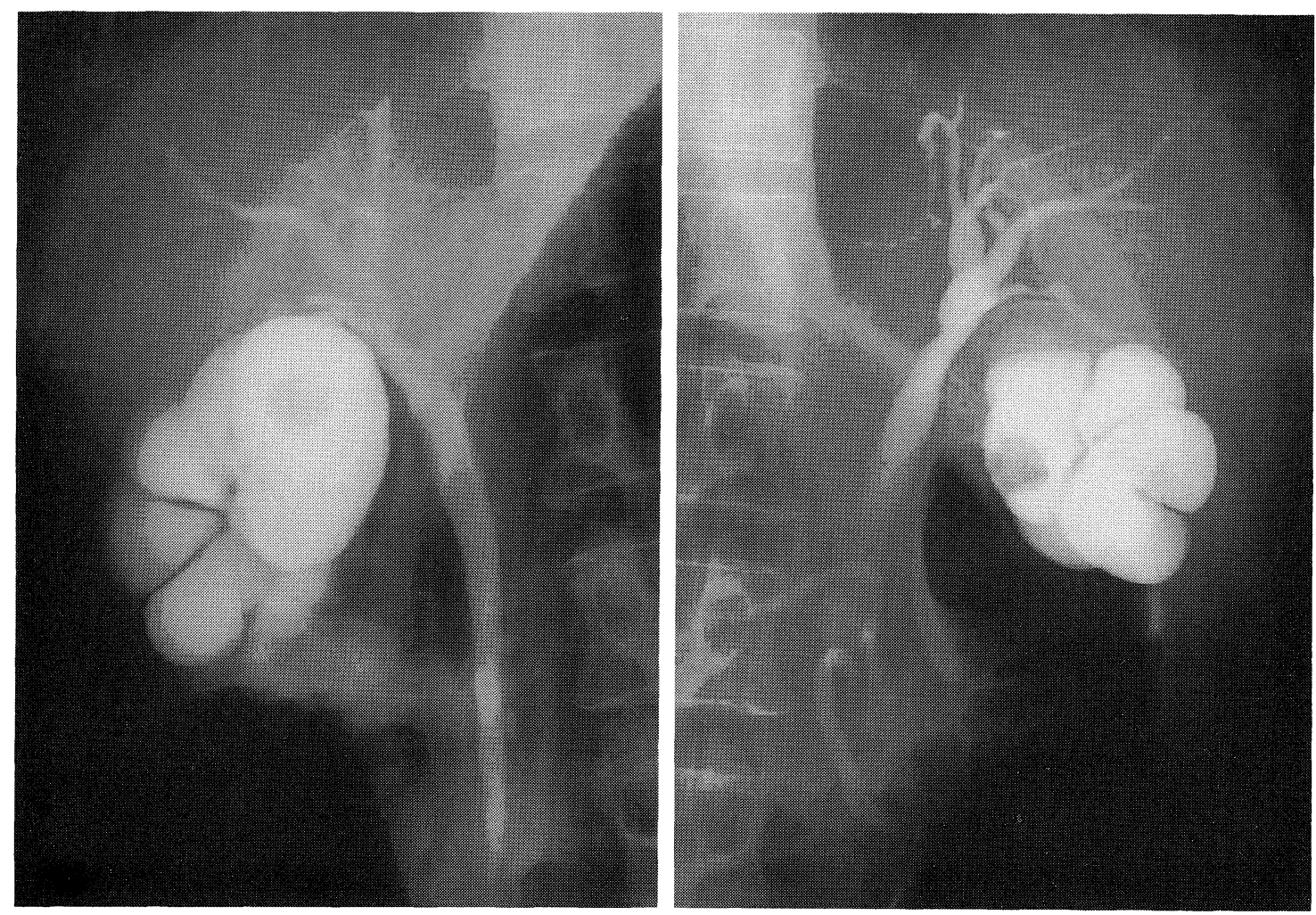

Figure 4. Endoscopic retrograde cholangiography demonstrates at least six septa dividing the gallbladder into multiple chambers. The solitary gallstone is identified as a filling defect.

phocytes and plasma cells (Fig. 5). These findings were compatible with stage II primary biliary cirrhosis (8). Concomitant chronic hepatitis due to $\mathrm{HCV}$ infection was also suggested on the basis of the histological and serological findings. According to the new Inuyama classification of chronic hepatitis staging and grading categories revealed $\mathrm{F} 1$ and $\mathrm{A} 1$ respectively (9).

After two weeks of admission the patient was discharged under medication with ursodeoxycholic acid and an $\mathrm{H}_{2}$ receptor antagonist. During a follow-up period of 2 years in our outpatient department, the patient has remained asymptomatic.

\section{Discussion}

Gallbladders containing one to three septa are not unusual, being seen in approximately $4 \%$ of all patients undergoing cholecytography (10). However, multiseptate gallbladder is quite a rare anomaly. To our knowledge, the present case is the 26th described so far in the world literature, since the first description by Simon and Tandon (11) in 1963 (Table 2). The exact mechanism responsible for the genesis of multiseptation is not clear. However, it is speculated that wrinkling and infolding seen in the gallbladder buds of cat and guinea-pig embryos or formation of the so-called Phrygian cap in human embryos may be related to this phenomenon (15).

A review of the 26 cases revealed a female predominance

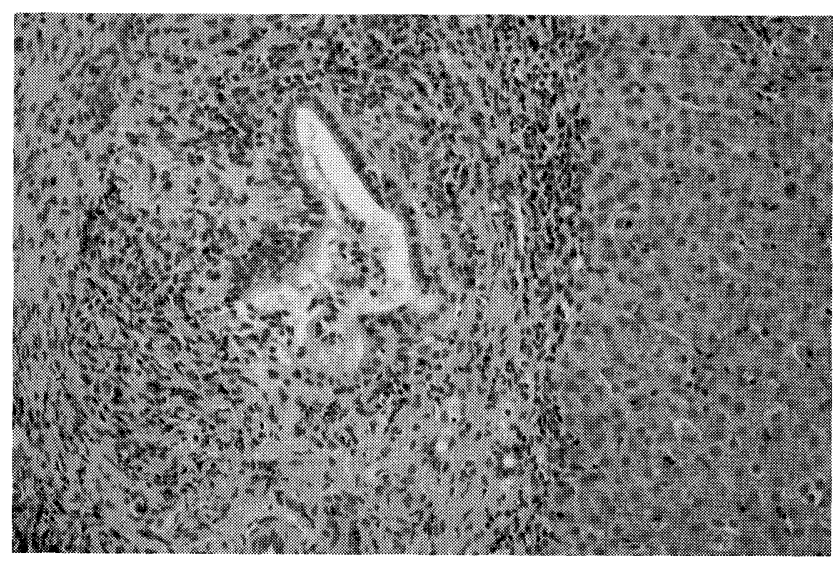

Figure 5. Needle biopsy of the liver $($ HE stain, $\times 80)$. The portal tract is enlarged with prominent interlobular bile duct damage. The infiltrating inflammatory cells consist of lymphocytes and plasma cells.

(male : female; $1: 3.3$ ) and a mean patient age of 32 years (range 8-70 year). The coexistence of biliary symptoms with multiseptate gallbladder has been well established, and most patients have colicky biliary pain suggestive of cholecystitis. However, histologically confirmed acute cholecystitis or ac- 
Miwa et al

Table 2. Reported Cases of Multiseptate Gallbladder

\begin{tabular}{|c|c|c|c|c|c|c|}
\hline Author (Reference) & Year & Age & Sex & $\begin{array}{c}\text { Biliary } \\
\text { symptoms }\end{array}$ & $\begin{array}{l}\text { Concomitant } \\
\text { biliary disease }\end{array}$ & Chlecystectomy \\
\hline Simon (11) & 1963 & 32 & $\mathrm{~F}$ & + & - & + \\
\hline Bigg (12) & 1964 & 38 & M & + & - & + \\
\hline Haslam (13) & 1966 & 15 & $\mathrm{~F}$ & + & - & + \\
\hline Sachsse (14) & 1968 & 50 & M & + & - & - \\
\hline Bhagavan (15) & 1970 & 27 & $\mathrm{~F}$ & + & Hypoplasia of gallbladder & + \\
\hline Croce (1) & 1973 & 45 & $\mathrm{~F}$ & + & Cholelithiasis & + \\
\hline Codinach (2) & 1975 & 28 & $\mathrm{~F}$ & + & Cholelithiasis & + \\
\hline Shaw (16) & 1975 & 31 & $\mathrm{~F}$ & + & - & + \\
\hline Konishi (17) & 1977 & 51 & $\mathrm{~F}$ & + & - & + \\
\hline Jena (18) & 1977 & 28 & $\mathrm{~F}$ & + & Hypoplasia of gallbladder & + \\
\hline Okuda (19) & 1979 & 38 & M & + & - & + \\
\hline Alawneh (3) & 1981 & 44 & $\mathrm{~F}$ & + & Cholelithiasis & + \\
\hline Toombs (20) & 1982 & 22 & $\mathrm{~F}$ & + & - & + \\
\hline Oliva $(21)$ & 1985 & 24 & $\mathrm{~F}$ & + & - & + \\
\hline Pery (22) & 1985 & 8 & $\mathrm{~F}$ & + & Choledochal cyst & + \\
\hline Lev-Toaff (23) & 1987 & 30 & M & - & - & - \\
\hline Lev-Toaff (23) & 1987 & 23 & $\mathrm{~F}$ & - & - & - \\
\hline Fremond (4) & 1989 & 13 & $\mathrm{~F}$ & + & - & + \\
\hline Adear (24) & 1990 & 12 & $\mathrm{~F}$ & - & - & - \\
\hline Isomoto $(25)$ & 1990 & 43 & $\mathrm{~F}$ & + & - & + \\
\hline Vasinrappee (26) & 1990 & 24 & M & + & - & not described \\
\hline $\operatorname{Tan}(5)$ & 1993 & 14 & $\mathrm{~F}$ & + & Choledochal cyst & + \\
\hline Hahm (27) & 1994 & 49 & $\mathrm{~F}$ & + & - & - \\
\hline Naritomi (28) & 1994 & 45 & $\mathrm{~F}$ & + & - & + \\
\hline Saimura (29) & 1996 & 30 & M & + & - & + \\
\hline Present case & 1999 & 70 & $\mathrm{~F}$ & - & Cholelithiasis, PBC & - \\
\hline
\end{tabular}

companying cholelithiasis are very infrequent in patients with multiseptate gallbladder. Only four patients, including the present one, had gallstones (1-3). The optimal treatment of symptomatic patients with multiseptate gallbladder is considered to be cholecystectomy, and the patients who underwent this operation were invariably relieved of biliary pain.

The present 70-year-old female patient was by far the oldest of all those reported to date. Because she had been totally asymptomatic and had never undergone examination of the gallbladder, this congenital anomaly may have been left overlooked for a long period. It has been postulated that pain in patients with multiseptate gallbladder is due to mechanical problems. Transient inability of the viscid bile to pass through small openings in the septa may result in stasis, incomplete emptying and increased intraluminal pressure (15). Only four of the patients with multiseptate gallbladder, including the present one were asymptomatic $(23,24)$. Since the previous three patients were less than 30 years old, with a possibility of developing symptoms in the future, our 70-year-old patient provides good evidence that this clinical entity can sometimes remain entirely asymptomatic.

Except for gender and age, the established risk factors such as obesity, family history, hypertriglycerimia, and multiparity did not explain the occurrence of cholelithiasis in this patient. Association between rheumatoid arthritis and cholelithiasis has never been evident, although ingestion of NSAIDs is reported to prevent cholelithiasis $(30,31)$. Several studies have demonstrated a high prevalence of gallstones in patients with liver cirrhosis, especially primary biliary cirrhosis $(6,32,33)$. The present patient had two concomitant chronic liver diseases: asymptomatic primary biliary cirrhosis and chronic hepatitis C. These two liver disorders probably had little relationship with the genesis of cholelithiasis, because the gallstone had been present for more than 20 years and thus occurred earlier than any possible lithogenic effect of chronic liver disease, considering the minimal degree of liver damage at presentation.

Calculus formation might be a more frequent finding in older patients with multiseptate gallbladder. In fact, the mean age of the four patients exhibiting cholelithiasis was higher than that of the other patients without cholelithiasis. Croce (1) proposed that the anomaly may become manifest at an earlier age than calculus disease because of the underlying mechanical problems of bile concentration and stasis in the various chambers.

We have thus presented a rare case of multiseptate gallbladder with a full description of the characteristic radiologic features and a review of the related literature. This case was unique in that the patient was elderly and asymptomatic with cholelithiasis. 


\section{References}

1) Croce EJ. The multiseptate gallbladder. Arch Surg 107: 104-105, 1973.

2) Codinach N, Sarles H, Sahe J, Alemanno J. La vesicule bilıaire multiseptale: Presentation d'un cas. Arch Fr Mal App Dig 64: 431-435, 1975.

3) Alawneh I, Baranzanchı I, Jacobi K. Mehrfach septierte Gallenblase als Ursache von koliken. Med Klın 76: 190-191, 1981

4) Fremond B, Stasik C, Jouan $H$, et al. The multıseptate gallbladder. A rare malformation of the biliary tract. Chir Pedıatr 30: 292-294, 1989.

5) Tan CE, Howard ER, Driver M, Murray-Lyon IM. Non-communicating multiseptate gallbladder and choledochal cyst: A case report and a review of publications. Gut 34 $853-856,1993$.

6) Summerfield JA, Elias E, Hungerford GD, Nikapota VL, Dick R, Sherlock S. The biliary system in primary biliary cirrhosis: A study by endoscopic retrograde cholangiopancreatography. Gastroenterology 70: 240-243, 1976.

7) Hamilton I, Lintott DJ, Ruddell WS, Axon AT. The endoscopic retrograde cholangiogram and pancreatogram in chronıc liver disease. Clin Radiol 34: 417-422, 1983.

8) Scheuer PJ. Primary biliary cirrhosis. Proc R Soc Med 60: 1257-1260, 1967.

9) Ichıda F, Tsuji T, Omata M, et al. New Inuyama classification; new criteria for histological assessment of chronic hepatitis. Int Hepatol Commun 6: 112-119, 1996.

10) Spech HJ, Hummer N, Braun H. Septierte gallenblasen. Med Klın 70: 941-946, 1975.

11) Simon M, Tandon BN. Multiseptate gallbladder: A case report. Radiology 80: 84-86, 1963.

12) Bigg RL. Multiseptate gallbladder. Arch Surg 88: 501-502, 1964.

13) Haslam RH, Gayler BW, Ebert PA. Multiseptate gallbladder. Am J Dis Child 112: 600-603, 1966.

14) Sachsse VW, Hıller W. Zur vielfach septierten Gallenblase; Kasuistischer Bettrag. Fortscher Rontgenstr 108: 547-548, 1968.

15) Bhagavan BS, Amin PB, Land AS, Weinberg T. Multiseptate gallbladder: Embryogenetic hypotheses. Arch Pathol 89: 382-385, 1970.

16) Shaw RB, Donato CA, Douglas DD, Sass JK, Montegut FJ. Multiseptate gallbladder diagnosed during pregnancy. Am Surg 41: 818-822, 1975.

17) Konishi F, Saito $H$, Asano A. A case report of multiseptate gallbladder.
Jpn J Gastroenterol 72: 1252-1256, 1975.

18) Jena PK, Hardie RA, Hobsley M. Multıseptate hypoplastic gallbladder. Br J Surg 64: 192-193, 1977.

19) Okuda K, Nakajima M, Nakayama M, Nomura F. Multiseptate gallbladder: Report of a case with a review of literature. Acta Hepato-Gastroenterol 26: 70-75, 1979.

20) Toombs BD, Foucar E, Rowlands BJ, Strax R. Multiseptate gallbladder. South Med J 75: 610-612, 1982.

21) Oliva Oliva I, Rodoliguez Moran M, Lozano Sanchez F, Gomez Alonso A. Multi-septate gallbladder. Int Surg 70: 83-84, 1985.

22) Pery M, Kaftori JK, Marvan H, Sweed Y, Kerner H. Ultrasonographic appearance of multiseptate gallbladder: Report of a case with coexisting choledochal cyst. J Clin Ultrasound 13: 570-573, 1985.

23) Lev-Toaff AS, Friedman AC, Rindsberg SN, Caroline DF, Maurer AH, Radecki PD. Multiseptate gallbladder: Incidental diagnosis on sonography. Am J Rouentogenol 148: 1119-1120, 1987.

24) Adear H, Barki Y. Multıseptate gallbladder in a child: Incidental diagnosis on sonography. Pediatr Radiol 20: 192, 1990.

25) Isamoto I, Matsunaga N, Ochi M, et al. Multiseptate gallbladder: Computed tomographic appearance. Radiat Med 8: 55-57, 1990.

26) Vasinrapee $P$, Linden $K$, Cook RE. Multiseptate gallbladder demonstrated on Tc-99m hepatobiliary imaging. Clin Nucl Med 15: 272, 1990.

27) Hahm KB, Yım DS, Kang JK, Park IS. Cholangiographic appearance of multiseptate gallbladder: Case report and a review of the literature. $J$ Gastroenterol 29: 665-668, 1994.

28) Naritomi G, Kimura H, Konomi H, et al. Multıseptate gallbladder as a cause of biliary pain. Am J Gastroenterol 89: 1891-1892, 1994.

29) Saimura M, Ichimiya H, Naritomi G, et al. Multiseptate gallbladder: Bıliary manometry and scintigraphy. J Gastroenterol 31: 133-136, 1996.

30) Lee SP, Carey MC, LaMont JT. Aspirin prevention of cholesterol gallstone formation in prarrie dogs. Science 211: 1429-1431, 1981.

31) Hood K, Gleeson D, Ruppin DC, Dowlıng RH. Prevention of gallstone recurrence by non-steroidal anti-inflammatory drugs. Lancet 2(8622): 1223-1225, 1988.

32) Conte D, Barisani D, Mandelli C, et al. Cholelithiasis in cirrhosis: Analysis of 500 cases. Am J Gastroenterol 86: 1629-1632, 1991.

33) Fleming CR, Ludwig J, Dickson ER. Asymptomatic primary bilıary cirrhosis: presentation, histology, and results with D-penicillamıne. Mayo Clın Proc 53: 587-593, 1978. 